\title{
Gray matter imaging in multiple sclerosis: what have we learned?
}

Hanneke E Hulst ${ }^{1,2^{*}}$ and Jeroen JG Geurts ${ }^{2}$

\begin{abstract}
At the early onset of the $20^{\text {th }}$ century, several studies already reported that the gray matter was implicated in the histopathology of multiple sclerosis (MS). However, as white matter pathology long received predominant attention in this disease, and histological staining techniques for detecting myelin in the gray matter were suboptimal, it was not until the beginning of the $21^{\text {st }}$ century that the true extent and importance of gray matter pathology in MS was finally recognized. Gray matter damage was shown to be frequent and extensive, and more pronounced in the progressive disease phases. Several studies subsequently demonstrated that the histopathology of gray matter lesions differs from that of white matter lesions. Unfortunately, imaging of pathology in gray matter structures proved to be difficult, especially when using conventional magnetic resonance imaging (MRI) techniques. However, with the recent introduction of several more advanced MRI techniques, the detection of cortical and subcortical damage in MS has considerably improved. This has important consequences for studying the clinical correlates of gray matter damage. In this review, we provide an overview of what has been learned about imaging of gray matter damage in MS, and offer a brief perspective with regards to future developments in this field.
\end{abstract}

\section{Background}

For many years, focal inflammatory demyelination in the white matter (WM) was considered the most important pathological 'hallmark' of multiple sclerosis (MS). However, demyelination in the cerebral cortex was already observed in early pathology studies by Sander (1898), Dinkler (1904), Schob (1907) and Dawson (1916) [1-4]. After these initial, largely casuistic, descriptions of demyelination in the gray matter (GM) of MS patients, the topic was largely disregarded. This was mostly due to difficulties involved with the visualization of cortical GM lesions in the post mortem setting, in which conventional histochemical staining procedures were applied, as well as to a predominant attention for the generally more conspicuous process of inflammatory WM demyelination.

However, by the start of the $21^{\text {st }}$ century, the focus within MS research slowly shifted back from WM to GM. In 2003, when new immunohistochemical staining techniques that improved the ex vivo detection of GM damage had become available, the presence and extent

\footnotetext{
* Correspondence: he.hulst@vumc.nl

'Department of Radiology, VU University Medical Centre, PO Box 7057, 1007 MB, Amsterdam, The Netherlands

Full list of author information is available at the end of the article
}

of GM demyelination was described in detail and pathophysiological processes causing GM damage, as well as its visualization with modern magnetic resonance imaging (MRI) techniques, became central issues in MS research (see Figure 1).

This review will focus on what has been learned in the past decade of imaging GM pathology in MS. As will be shown, visualization of GM demyelination was difficult at first, but improved upon technical developments in the field. An important question that now remains is whether MRI visualization of GM pathology in MS is sufficient, or whether further improvement is still needed.

\section{GM involvement in a WM disease}

After the first pivotal reports of GM damage in MS in the early 20th century, it was not until 1962 that Brownell and Hughes reported that $26 \%$ of the macroscopically visible lesions found in their post mortem material of 22 MS patients were (partly) located in or around the cortical and subcortical GM [5]. Extensive involvement of the cortex in MS patients was later confirmed in histopathology [6] and in a study combining post mortem MRI and conventional histology [7].

\section{Ciomed Central}




\section{(HISTO)PATHOLOGY}

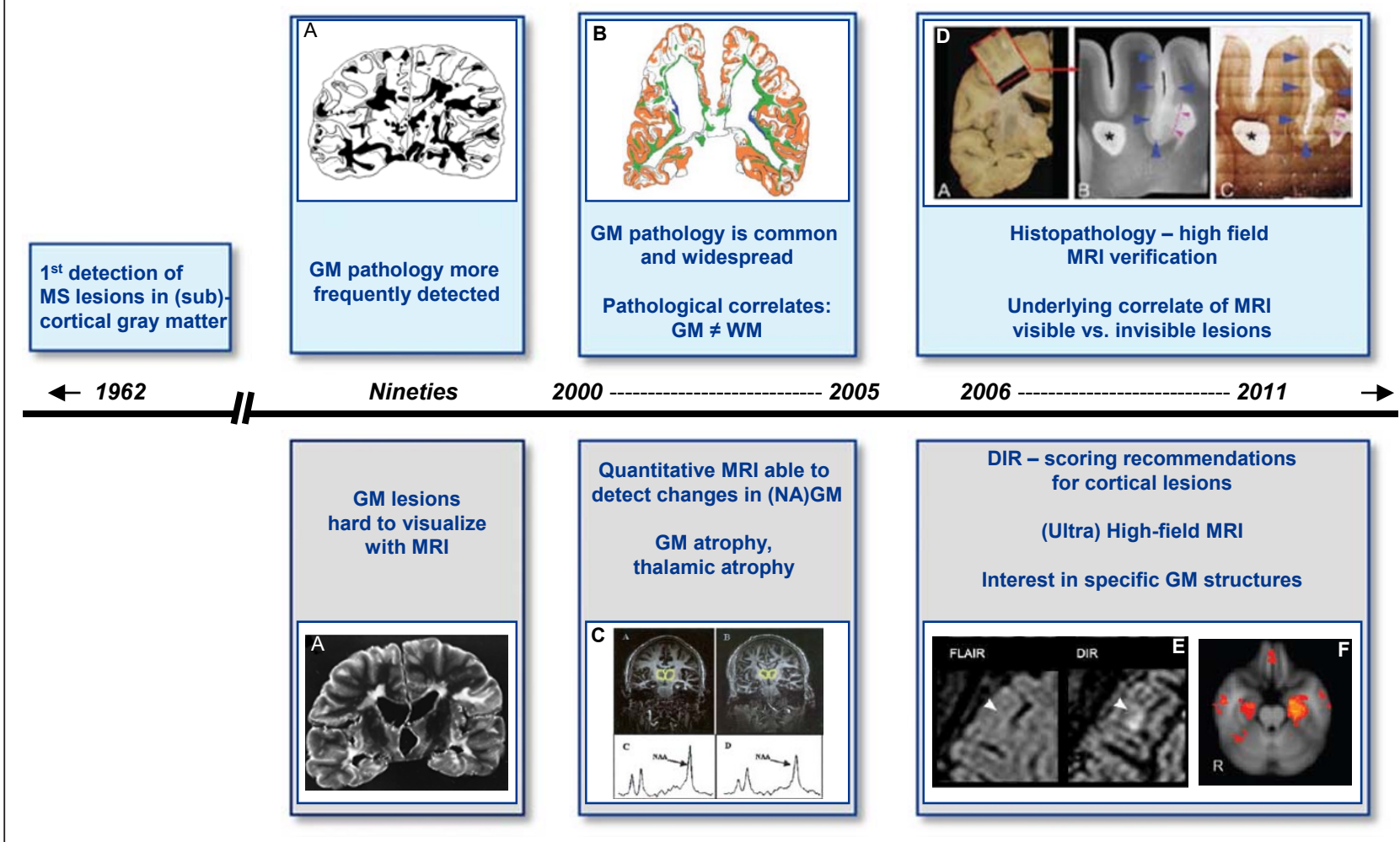

\section{NEUROIMAGING}

Figure 1 Timeline of GM imaging in MS. A schematic overview of developments in the field of GM imaging in MS from the beginning of the $20^{\text {th }}$ century until now. A, B, D) Reproduced from Kidd et al. [7], Kutzelnigg et al. [19], and Schmierer et al. [88] respectively, all with permission from Oxford University Press. C) Reproduced from Cifelli et al. [100] with permission from John Wiley and Sons. E, F) Reproduced from Geurts et al. [69] and Roosendaal et al. [126] respectively, both with permission of the Radiological Society of North America.

At that point in time, the detection of GM demyelination in tissue sections was difficult, as standard histochemical myelin stains like luxol fast blue (LFB) were not sufficiently adequate for visualization of changes in GM myelin density. Detection of GM pathology with conventional T2-weighted MRI also proved to be difficult because of the intrinsically low myelin density in the cortex, which generates little contrast between normal GM and demyelinated GM lesions, and because of the fact that cortical lesions may be small and partial volume effects with cerebrospinal fluid in the sulci can interfere with reliable lesion detection $[7,8]$. To improve the detection of cortical lesions on MRI, newer techniques like fast fluid-attenuated inversion recovery (FLAIR) MR sequence were used $[9,10]$. FLAIR improved lesion detection in the cortex and in (juxta) cortical areas as compared to conventional T2-weighted MRI [9-14]. However, the reported prevalence of cortical lesions on MRI was still much lower than that reported in post mortem studies [10].

\section{Description and classification of GM pathology in MS}

Histopathological detection of intracortical MS lesions improved with the use of myelin protein immunohistochemistry in the beginning of the $21^{\text {st }}$ century. Using immunohistochemistry for myelin basic protein (MBP) and proteolipid protein (PLP), Bö and colleagues shed more definitive light on the extent and distribution of cortical demyelination in MS $[15,16]$. In chronic MS cases myelin loss was found in $26.5 \%$ of their systematically examined areas of cerebral cortex [15]. The investigators proposed a classification system for cortical lesions which distinguished four different cortical lesion types: the mixed GM-WM (type I) lesions and the purely cortical (type II, III, and IV) lesions [16] (see Figure 2).

The pathology of GM lesions generally differs considerably from that of WM lesions. Lymphocyte infiltration, complement deposition, and blood-brain-barrier disruption have not been detected in GM lesions, whereas WM lesions are known to harvest substantial 


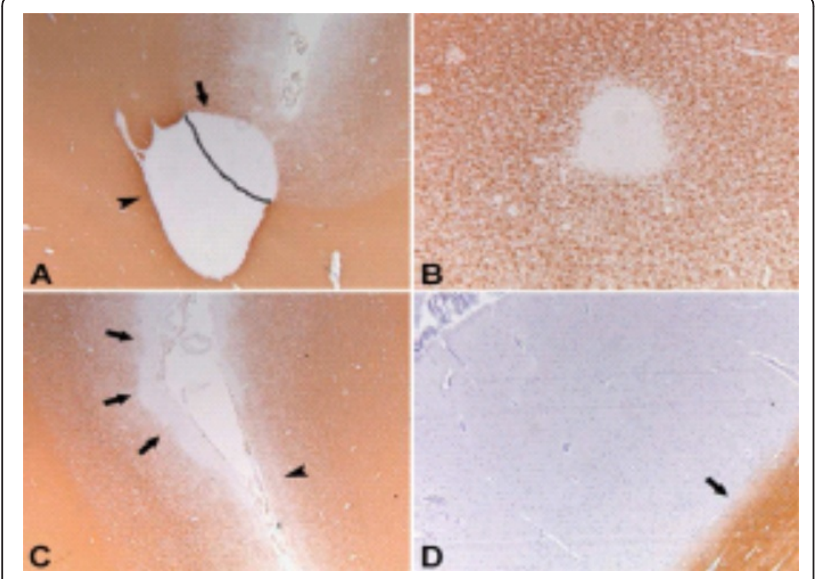

Figure 2 Pathological classification system of GM lesions in MS. GM lesion classification system as proposed by Bo et al,. 2003. Type 1 lesions (A) extend through both white and gray matter. Type 2 lesions (B) are intracortical, having no contact with white matter or with the surface of the brain. Type 3 lesions (C) extend inward from the surface of the brain. Type 4 lesions (D) extend through the whole width of the cortex without reaching into white matter. Reproduced from Geurts and Barkhof [131] with permission from Elsevier.

inflammation [16-18]. Another pivotal study by Kutzelnigg and colleagues showed demyelination of the MS cortex and reported extreme cases with more than $70 \%$ of cortical demyelination [19]. Besides demyelination in the cerebral cortex, demyelination was later also found in the cerebellum [20], in deep gray matter structures $[21,22]$, and in the GM of the spinal cord [23].

Pathological studies demonstrated that cortical demyelination is most frequent and extensive in patients with a longer disease duration (secondary progressive MS; SPMS) and with a more progressive form of MS (primary progressive MS, PPMS), whereas it was found to be rare in relapsing remitting MS patients (RRMS) $[19,21]$. However, GM demyelination was recently found in biopsy material of an early MS patient, even before disseminated WM lesions on MRI became visible [24].

Although histopathological studies had improved as a result of the new staining methods, GM lesions remained extremely difficult to detect on conventional MRI. For example, it was shown that T2-weighted and FLAIR imaging detected only 3 to $5 \%$ of a total of 63 histopathologically defined cortical lesions [25]. Nevertheless, the (juxta)cortical lesions that were detected with these MRI sequences were clearly associated with cognitive impairment, epilepsy, depression, fatigue, and physical disability in MS patients [26-32].

In parallel, MRI studies focused on imaging the normal appearing GM of MS patients (NAGM; i.e., GM that looks normal on conventional T2-weighted MRI, but might nevertheless be histopathologically abnormal) using more advanced, quantitative MRI techniques. These techniques are generally more sensitive to (subtle) pathology in the GM than conventional MRI sequences [33]. Clinically relevant abnormalities in the NAGM of MS patients were reported with magnetization transfer imaging (MTI) [34-37], T1-relaxometry [38,39], diffusion tensor imaging (DTI) $[40,41]$, and proton magnetic resonance spectroscopy (MRS) [42-44] in both cortical and subcortical GM areas in MS. These measured abnormalities most likely reflect subtle tissue changes due to lesions or independent from lesions.

To sum up, around the turn of the century, GM pathology in MS became increasingly recognized as an important pathological hallmark in this 'typical' WM disease. The introduction of new histopathological staining methods improved the visualization of GM damage and revealed that GM demyelination was frequent, widespread, and more extensive in patients with longer disease duration. The pathological substrate of GM lesions was found to be different from WM lesions, as GM lesions are largely non-inflammatory. On conventional MRI, only a minority of GM lesions could initially be visualized. However, these lesions were associated with clinical deterioration. Besides cortical lesions, quantitative MRI also demonstrated clinically relevant abnormalities in the NAGM of MS patients.

\section{GM atrophy and cortical thinning}

Whereas the detection of focal GM lesions was difficult using conventional MRI measures, GM atrophy measurements proved to be robust and reliable using standard MRI sequences [33]. Automated methods to estimate brain volume were reproducible, both within and between research centres $[45,46]$. Decreased GM tissue volume, as well as cortical thinning, were found in MS patients compared to healthy age-matched controls and were observed already early in the disease course and across different MS types [47-59]. In a longitudinal study it was shown that whole brain atrophy rates were similar over time in stable Clinically Isolated Syndrome (CIS) patients, but steadily increasing as diseased severity increased (RRMS and SPMS) [60]. Interestingly, a significant and disproportionate increase in GM atrophy occurs in MS patients in more advanced disease stages [55,61], while WM atrophy rates accumulate more constantly over time [60]. GM atrophy and cortical thinning were significantly associated with physical disability and cognitive decline [47-50,55,56,62-66], and importantly, measures of GM atrophy showed stronger correlations with clinical parameters than WM damage $[56,60,61,66]$.

\section{New imaging techniques to detect cortical GM lesions}

In 1994, a new MRI sequence, the double inversion recovery (DIR), was introduced. This technique provided 
excellent distinction between the cerebral cortex and the WM in the healthy human subjects by suppression of the signal from WM and the cerebrospinal fluid (CSF) [67]. DIR proved to be superior in comparison to FLAIR where it concerned intratentorial lesions and lesions with low contrast on T2-weighted MR sequences [68]. However, it was not until several years later that DIR was applied to image GM pathology in MS [69]. In 2005, MR imaging with a 3D DIR sequence demonstrated increased intracortical lesion detection in the MS brain, as well as improved distinction between juxtacortical and mixed WM-GM lesions. A relative gain of $152 \%$ of DIR over FLAIR was described in the detection of cortical lesions [69]. Using DIR at a higher field strength (3T) led to an even further increase of detected cortical lesions in MS patients [70].

A series of important scientific contributions by Calabrese and colleagues subsequently confirmed histopathology studies by reporting that intracortical lesions detected on DIR are already present early in the disease [71-74] and are found in both relapse-onset and PPMS patients $[74,75]$. The investigators further showed that cortical lesions are most frequently found in SPMS patients, in patients of the male sex, and in patients who also had IgG oligoclonal bands in the CSF [76,77]. A relative sparing of the cortex was found for patients with benign MS [72]. The presence of cortical lesions was associated with clinical disability, brain volume loss and/or cognitive impairment [73,75-79]. Longitudinal DIR studies showed an increase in cortical lesion number and/or an increase in lesion size over time $[73,75,77,80]$.

These results notwithstanding, the use of different DIR sequences and different lesion scoring criteria in different research centres made the comparison of available cortical lesion data in the literature challenging. Therefore, in an attempt to improve consistency of cortical lesion scoring between raters and centres using DIR, international cortical lesion scoring guidelines were proposed $[81,82]$. These DIR scoring guidelines were subsequently verified in the post mortem setting and showed that although DIR is highly pathologically specific $(90 \%$ of cortical hyperintensities identified related to actual lesions in post mortem tissue), the sensitivity of DIR is rather poor [82]. Especially subpial cortical lesions were found to be difficult to detect on DIR.

So far, no specific pathological properties were found that determine whether cortical lesions become MRIvisible or MRI-invisible. Instead, it was shown that the visibility of cortical lesions on MRI is predominantly determined by their size. Furthermore, MRI-visible cortical lesions were strongly associated with a higher total cortical lesion load in brain tissue specimens, which suggests that when cortical lesions become visible on MRI, they merely reflect 'the tip of the pathological iceberg' [83].

Other studies aiming to improve visualization of cortical GM lesions used phase-sensitive inversion recovery (PSIR) and 3D T1 weighted sequences [84,85]. Future post mortem work will have to show whether sensitivity and specificity for cortical GM lesions may further improve when combinations of T1-based techniques, PSIR and DIR are used, when compared to DIR alone. Ideally, this would lead to a recommendation as to which (combination of) technique(s) should be used to optimally visualize (cortical) GM pathology in vivo, and further increase our understanding about the role of GM damage in clinicocognitive deterioration in MS.

\section{High-field and ultrahigh-field MRI}

With the introduction of (ultra) high-field MRI, signalto-noise ratio, spatial resolution, and image contrast improved, which all benefited the detection of GM lesions [86-88]. In vivo studies using 2D T2*-weighted gradient-echo and 3D T1-weighted magnetization-prepared rapid-acquisition GRE sequences at 7T or higher were able to provide high-resolution anatomical images of cortical lesions [89-91]. It was recommended that a combination of MR sequences be used at higher field strength, as different techniques may provide complementary information in the definition of cortical lesions [92]. Furthermore, and this is new when compared to standard field, it was shown that ultra high-field MRI enables accurate visualization of subpial GM lesions $[15,88,91]$.

\section{Non-neocortical GM damage}

MRI and histopathology studies showed that atrophy and demyelinated lesions do not only exist in the cortical GM but also in other GM structures such as the thalamus, hippocampus, caudaute, putamen, pallidum, claustrum, hypothalamus, amygdala and substantia nigra [21-23,42,93-105], see Figure 3. Hypothalamic lesions were found to be numerous in a post mortem MS dataset [96] and higher inflammatory activity of hypothalamic lesions was associated with a worse disease course [97].

Of all the GM structures, the thalamus has been studied most extensively with MRI [21,22,42,99-110]. One of the reasons that the thalamus received broad attention is because of the extensive reciprocal connections with the cortex and subcortical structures which makes this brain structure particularly sensitive to pathological changes in other areas of the brain [100]. Several studies focused on the volume of non-neocortical GM structures and showed thalamic atrophy in all different MS disease types [102-104,106-109,111-113] (see Figure 3). In CIS patients, thalamic atrophy was already present 


\section{Effect sizes of subcortical atrophy}
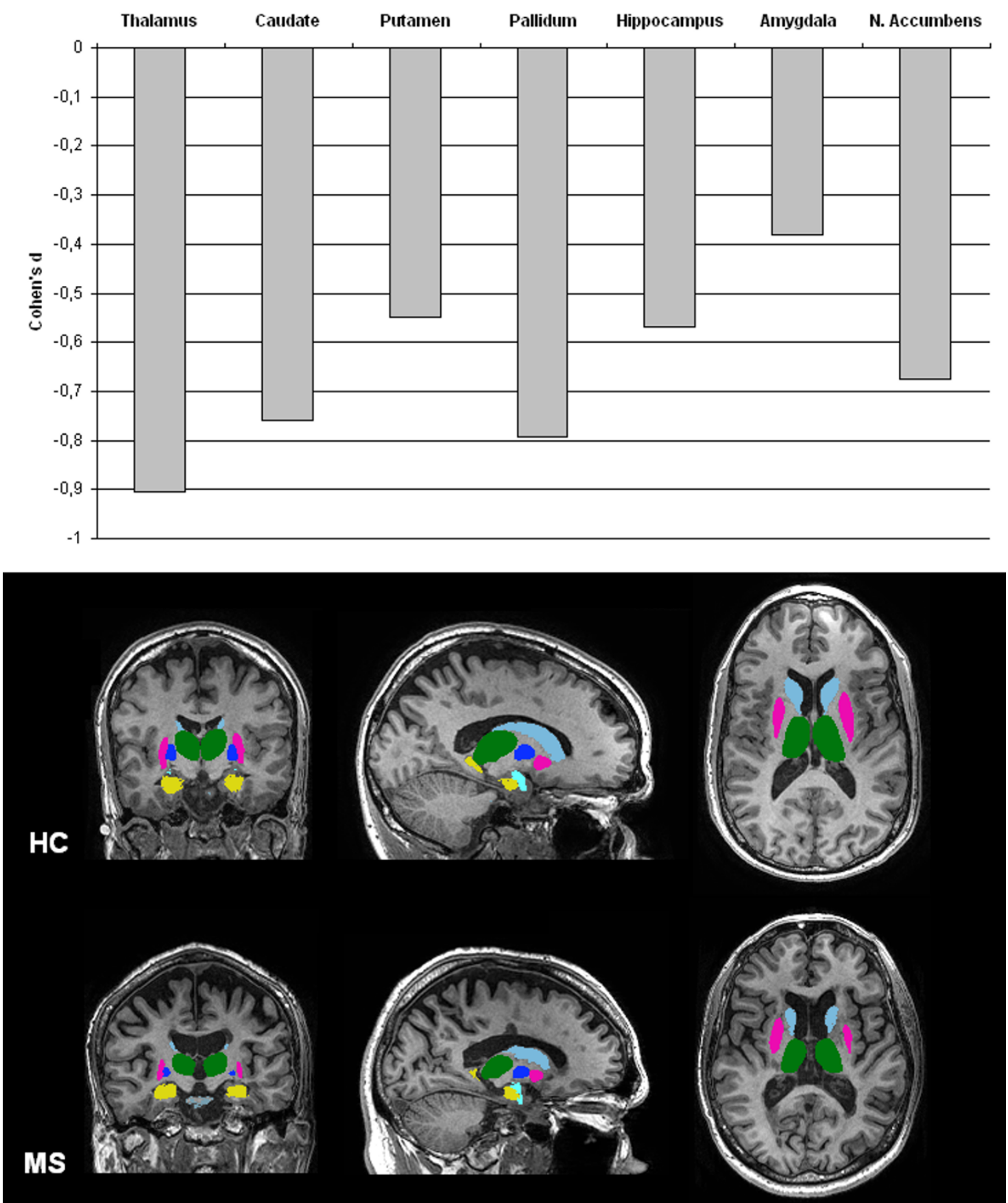

Figure 3 Subcortical GM damage in MS. Subcortical atrophy, measured using FIRST (part of FSL 4.1: http://www.fmrib.ox.ac.uk/fsl/). Above: Effect sizes of subcortical atrophy in a cohort of 120 early RRMS patients, six years post-diagnosis. Below: Two examples of segmented subcortical structures in a healthy control (HC, above) and an age-matched RRMS patient (MS, below).

$[103,104,108,112]$, and interestingly a reduction in thalamic fraction was more pronounced in RRMS patients compared to SPMS patients [104]. Additionally, in a longitudinal study thalamic atrophy was found to be more pronounced in RRMS patients compared to regional cortical atrophy [111]. This indicates that neuronal damage in the thalamus occurs early in the disease course. In terms of clinical relevance, thalamic atrophy 
has been associated with disability, cognitive impairment, and fatigue $[99,104,107,110]$. Furthermore, thalamic atrophy was seen in paediatric MS patients and PPMS patients as well $[109,113,114]$. Using quantitative MR techniques, changes in the chemical composition of thalamic tissue could be detected. A reduction of $\mathrm{N}$ acetylaspartate (NAA) in the thalamus was found with MRS and is thought to reflect neuro-axonal loss $[42,100,102]$. MTI showed a reduced magnetization transfer ratio (MTR) in the thalamus, an abnormality which was already found within the first five years of the disease [101,104]. And also changes in thalamic DTI measures were partly associated with disability, brain volume, and lesion load [105].

The hippocampus was found to be a predilection site for GM demyelination in MS $[21,95,115]$. In vivo, areas of signal abnormality in the hippocampus were also identified by using DIR [116], as well as increased levels of myo-inositol using MRS [42]. In addition, hippocampal atrophy was found in RRMS, SPMS, and PPMS patients, imaged at $1.5 \mathrm{~T}$ and $3 \mathrm{~T}[117,118]$. At 3T, atrophy was reported to start in the cornu ammonis 1 (CA1) region of the hippocampus in RRMS, only to expand to other CA regions in more advanced stages of the disease (SPMS) [118].

Besides structural differences in the MS brain, functional changes can be studied as well by using e.g. functional MRI (fMRI). Different cognitive paradigms for task-fMRI have been used so far, as well as resting-state fMRI. Several differences between healthy controls and MS patients were found in terms of brain activation and brain connectivity [119-125]. Some fMRI studies focused on a particular GM brain structure or functional anatomical system rather than on a specific cognitive domain. For example, reduced functional connectivity was reported between the hippocampus and its anatomical input c.q. target areas, including the anterior cingulate gyrus, thalamus, and prefrontal cortex. These changes were more pronounced in MS patients with hippocampal atrophy, but were also detected in patients without hippocampal volume loss [126]. Additionally, in a taskspecific fMRI study, differences in hippocampal function during a memory encoding task were detected between MS patients with and MS patients without cognitive decline. These findings were independent of differences in hippocampal volume and number of hippocampal lesions [127] (see Figure 4).

To summarize, during the past few years, the number of studies investigating GM damage in MS has tremendously increased. GM atrophy and cortical thinning were shown to be robust and reliable measures. GM atrophy correlated more strongly than WM atrophy with disability and cognitive impairment. New imaging techniques, such as DIR, improved the detection of cortical lesions in vivo. With the introduction of (ultra) high-field MRI, the visualization of cortical lesions improved even further. Recently published international consensus guidelines for scoring cortical lesions on DIR will likely increase the consistency between different research groups, and will improve the comparability of different DIR studies. Post mortem work demonstrated that DIR is pathologically specific, but lacks sensitivity. This means that many cortical lesions are still missed and MRI detects only 'the tip of the pathological iceberg'. Despite their under representation on MRI, cortical lesions were shown to be clinically relevant. Both imaging and histopathology studies showed that GM damage in MS is not limited to the neocortex; the cerebellum, spinal cord, and non-neocortical GM structures are affected as well.

\section{A brief future perspective of GM imaging in MS}

From a pathological point of view, it is clear that GM damage is common, widespread, and different from WM damage. A challenging next step is to investigate the cause(s) of GM pathology. For example, whether damage to the GM develops purely as a result of inflammatory demyelination in the WM or whether pathological processes in these two compartments of the brain are less connected than formerly thought, still remains to be elucidated [128-130].

As discussed in this review, from the neuroimaging perspective, MRI techniques have substantially improved over the past years and several new imaging modalities to better detect GM abnormalities are now available. It is possible to visualize cortical lesions with DIR, T1based or phase-sensitive sequences, as well as with (ultra) high-field MRI. Moreover, GM tissue loss can be reliably measured with the help of conventional MR sequences, and more subtle tissue changes can be observed with quantitative MRI. Finally, the function of specific GM structures or functional systems, as well as functional and structural connectivity changes within the brain can be imaged with MRI. With all these different imaging techniques to visualize GM pathology in vivo, it now remains to be determined which image modality, or combination of imaging modalities, best explains or predicts clinical symptomatology, and whether these techniques can be reliably used to monitor future treatment effects. Furthermore, the spatiotemporal relation between structural and functional changes, as well as changes in network dynamics in the brain as a consequence of disease will be difficult but exciting topics for future research in this field. The past few years of GM imaging research have seen tremendous progress; with the knowledge and technology now available, it is likely that ongoing joint efforts between different fields of research will create an even greater 

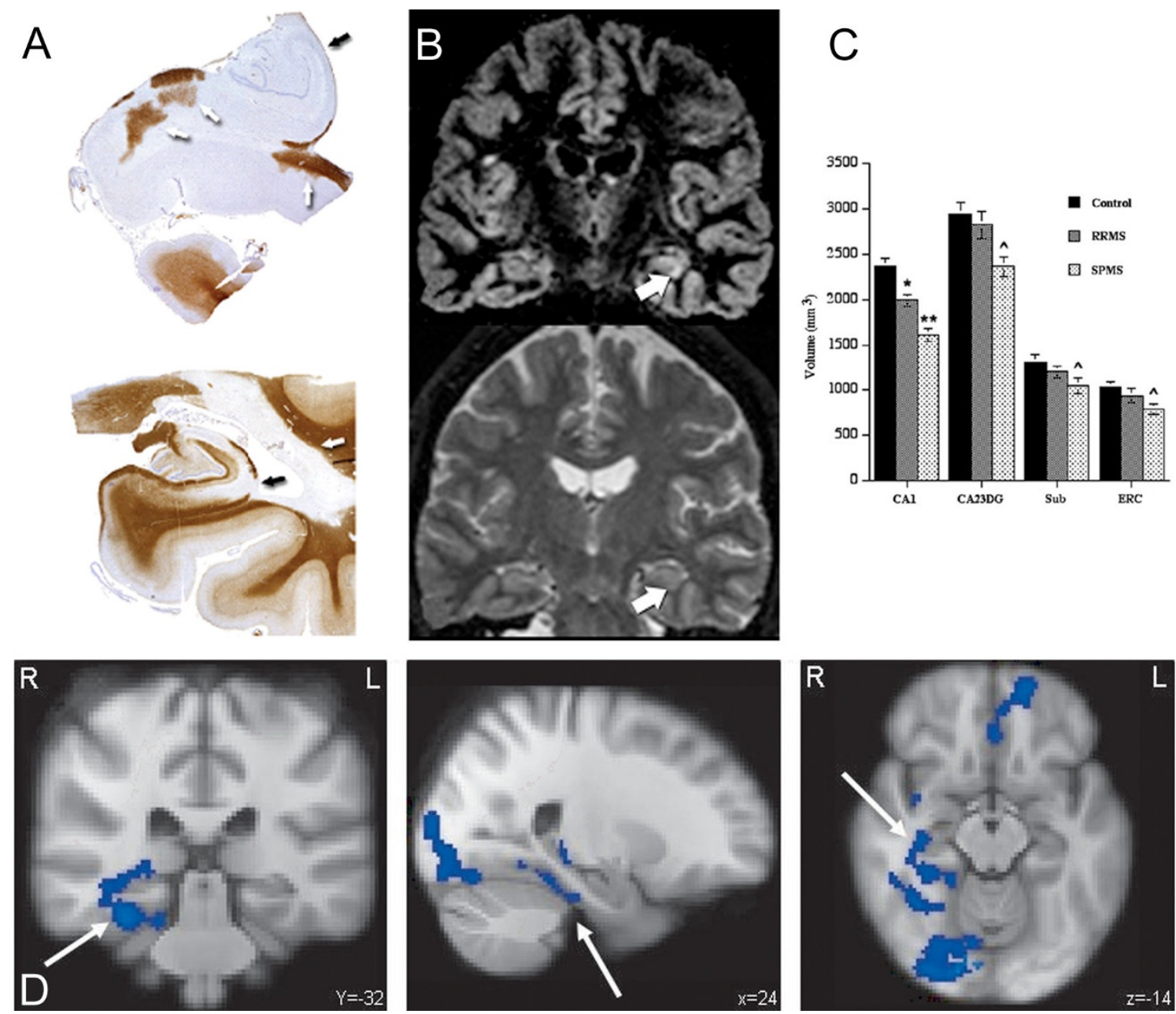

Figure 4 Non-neocortical GM damage: the hippocampus. A) Extensive hippocampal demyelination observed in post-mortem material. Reproduced from Geurts et al. [95] with permission from the American Association of Neuropathologists Inc. B) In vivo detection of hippocampal lesions using DIR imaging. Reproduced from Roosendaal et al. [116] with permission from John Wiley and Sons. C) Hippocampal atrophy on high field MRI provides detailed information on the specific location in the hippocampus where atrophy is present. Reproduced from Sicotte et al. [118] with permission from Oxford University Press. D) Anno 2011 it is besides structural changes also possible to study functional changes in the hippocampus; the blue areas indicates reduced hippocampal activity in cognitively impaired MS patients compared to healthy controls. Reproduced from Hulst et al. [127] with permission from John Wiley and Sons.

understanding of the role of GM pathology in MS in the near future.

\section{Conclusions}

What have we learned in GM imaging in MS?

- GM damage in MS is common and widespread, especially in chronic MS;

- The underlying pathological correlates of GM damage in MS are different from WM damage;

- GM pathology is present in all stages of the disease, but is more prominent in SPMS and PPMS compared to RRMS;

- Although a relatively non-specific measure of overall pathology, GM atrophy measurements are reliable and robust and correlate strongly with disability and cognitive impairment (more so than WM atrophy);

- Cortical lesions are of clinical relevance and are associated with a worse physical and cognitive performance;

- Cortical lesions have been difficult to visualize with conventional MRI, but due to newer imaging techniques (like DIR) lesion detection improved;

- Post mortem DIR verification showed high specificity of DIR lesions and increased sensitivity compared to conventional MR sequences; however, a substantial number of cortical lesions is still missed with in vivo MRI; 
- International consensus guidelines on DIR cortical lesion scoring will likely improve the comparability of different DIR studies;

- (Ultra) high-field MRI holds promise for more precise detection of cortical lesions, with maybe even the possibility to categorize GM lesions in vivo according to the pathological classification system used post mortem; especially the detection of subpial lesions (type III lesions) is likely to benefit from the use of (ultra) high-field MR imaging;

- Non-neocortical GM damage is frequently detected in histopathological studies as well as on MRI. Thalamic and hippocampal abnormalities have been studied most extensively and were shown to correlate with clinical parameters;

- Besides structural changes in the GM of MS patients, functional changes can be detected as well by using fMRI; this should shed more light on the relationship between functional and structural changes in the MS brain in future studies.

\section{Acknowledgements}

We thank the Dutch MS Research Foundation for supporting HEH (grant numbers: 02-358b, 08-648) and we thank Menno M. Schoonheim for providing Figure 3

\section{Author details}

'Department of Radiology, VU University Medical Centre, PO Box 7057, 1007 MB, Amsterdam, The Netherlands. ${ }^{2}$ Department of Anatomy and

Neurosciences, section of Clinical Neuroscience, VU University Medical

Centre, Van der Boechorststraat 7, 1081 BT Amsterdam, The Netherlands.

\section{Authors' contributions}

HEH and JJGG participated in the preparation of the manuscript. All authors read and approved the final manuscript.

\section{Competing interests}

The authors declare that they have no competing interests.

Received: 10 October 2011 Accepted: 12 December 2011 Published: 12 December 2011

\section{References}

1. Sander M: Hirnrindenbefunde bei multipler Sklerose. Monatschrift Psychiatrie Neurol 1898, IV:427-436

2. Schob F: Ein Beitrag zur patologischen Anatomie der multiplen Sklerose. Monatschrift Psychiatrie Neurol 1907, 22:62-87.

3. Dinkler M: Zur Kasuistik der multiplen Herdsklerose des Gehirns und Ruckenmarks. Deuts Zeits $f$ Nervenheilk 1904, 26:233-247.

4. Dawson JW: The Histology of Multiple Sclerosis. Trans $R$ Soc Edinburgh 1916, 50:517-740.

5. Brownell B, Hughes JT: The distribution of plaques in the cerebrum in multiple sclerosis. J Neurol Neurosurg Psychiatry 1962, 25:315-320.

6. Lumsden CE: The neuropathology of multiple sclerosis. In Handbook of clinical neurology. Edited by: Vinken PJ, Bruyn GW. Amsterdam, NorthHolland; 1970:217-309.

7. Kidd D, Barkhof F, McConnell R, Algra PR, Allen IV, Revesz T: Cortical lesions in multiple sclerosis. Brain 1999, 122(Pt 1):17-26

8. Newcombe J, Hawkins CP, Henderson CL, Patel HA, Woodroofe MN Hayes GM, Cuzner ML, MacManus D, du Boulay EP, McDonald WI: Histopathology of multiple sclerosis lesions detected by magnetic resonance imaging in unfixed postmortem central nervous system tissue. Brain 1991, 114(Pt 2):1013-1023.

9. Rovaris M, Yousry T, Calori G, Fesl G, Voltz R, Filippi M: Sensitivity and reproducibility of fast-FLAIR, FSE, and TGSE sequences for the MRI assessment of brain lesion load in multiple sclerosis: a preliminary study. J Neuroimaging 1997, 7:98-102.

10. Boggild MD, Williams R, Haq N, Hawkins CP: Cortical plaques visualised by fluid-attenuated inversion recovery imaging in relapsing multiple sclerosis. Neuroradiology 1996, 38(Suppl 1):S10-S13.

11. Gawne-Cain ML, O'Riordan JI, Thompson AJ, Moseley IF, Miller DH: Multiple sclerosis lesion detection in the brain: a comparison of fast fluidattenuated inversion recovery and conventional $\mathrm{T} 2$-weighted dual spin echo. Neurology 1997, 49:364-370.

12. Filippi M, Yousry T, Baratti C, Horsfield MA, Mammi S, Becker C, Voltz R, Spuler S, Campi A, Reiser MF, Comi G: Quantitative assessment of MRI lesion load in multiple sclerosis. A comparison of conventional spinecho with fast fluid-attenuated inversion recovery. Brain 1996, 119(Pt 4):1349-1355.

13. Tubridy N, Molyneux PD, Moseley IF, Miller DH: The sensitivity of thin-slice fast spin echo, fast FLAIR and gadolinium-enhanced T1-weighted MRI sequences in detecting new lesion activity in multiple sclerosis. J Neurol 1999, 246:1181-1185.

14. Bakshi R, Ariyaratana S, Benedict RH, Jacobs L: Fluid-attenuated inversion recovery magnetic resonance imaging detects cortical and juxtacortical multiple sclerosis lesions. Arch Neurol 2001, 58:742-748.

15. Bo L, Vedeler CA, Nyland HI, Trapp BD, Mork SJ: Subpial demyelination in the cerebral cortex of multiple sclerosis patients. J Neuropathol Exp Neurol 2003, 62:723-732.

16. Bo L, Vedeler CA, Nyland H, Trapp BD, Mork SJ: Intracortical multiple sclerosis lesions are not associated with increased lymphocyte infiltration. Mult Scler 2003, 9:323-331.

17. Brink $B P$, Veerhuis $R$, Breij $E C$, van d V, Dijkstra CD, Bo L: The pathology of multiple sclerosis is location-dependent: no significant complement activation is detected in purely cortical lesions. J Neuropathol Exp Neurol 2005, 64:147-155.

18. van Horssen J, Brink BP, de Vries HE, van d V, Bo L: The blood-brain barrier in cortical multiple sclerosis lesions. J Neuropathol Exp Neurol 2007, 66:321-328.

19. Kutzelnigg A, Lucchinetti CF, Stadelmann C, Bruck W, Rauschka H, Bergmann M, Schmidbauer M, Parisi JE, Lassmann H: Cortical demyelination and diffuse white matter injury in multiple sclerosis. Brain 2005, 128:2705-2712

20. Kutzelnigg A, Faber-Rod JC, Bauer J, Lucchinetti CF, Sorensen PS, Laursen $H$ Stadelmann C, Bruck W, Rauschka H, Schmidbauer M, Lassmann H: Widespread demyelination in the cerebellar cortex in multiple sclerosis. Brain Pathol 2007, 17:38-44

21. Vercellino M, Plano F, Votta B, Mutani R, Giordana MT, Cavalla P: Grey matter pathology in multiple sclerosis. J Neuropathol Exp Neurol 2005, 64:1101-1107.

22. Vercellino M, Masera S, Lorenzatti M, Condello C, Merola A, Mattioda A, Tribolo A, Capello E, Mancardi GL, Mutani R, Giordana MT, Cavalla P. Demyelination, inflammation, and neurodegeneration in multiple sclerosis deep gray matter. J Neuropathol Exp Neurol 2009, 68:489-502.

23. Gilmore CP, Donaldson I, Bo L, Owens T, Lowe J, Evangelou N: Regiona variations in the extent and pattern of grey matter demyelination in multiple sclerosis: a comparison between the cerebral cortex, cerebellar cortex, deep grey matter nuclei and the spinal cord. I Neurol Neurosurg Psychiatry 2009, 80:182-187.

24. Popescu BF, Bunyan RF, Parisi JE, Ransohoff RM, Lucchinetti CF: A case of multiple sclerosis presenting with inflammatory cortical demyelination. Neurology 2011, 76:1705-1710

25. Geurts JJ, Bo L, Pouwels PJ, Castelijns JA, Polman CH, Barkhof F: Cortical lesions in multiple sclerosis: combined postmortem MR imaging and histopathology. AJNR Am J Neuroradiol 2005, 26:572-577.

26. Christodoulou C, Krupp LB, Liang Z, Huang W, Melville P, Roque C, Scherl WF, Morgan T, MacAllister WS, Li L, Tudorica LA, Li X, Roche P, Peyster R: Cognitive performance and MR markers of cerebral injury in cognitively impaired MS patients. Neurology 2003, 60:1793-1798.

27. Feinstein A, Roy P, Lobaugh N, Feinstein K, O'Connor P, Black S: Structural brain abnormalities in multiple sclerosis patients with major depression. Neurology 2004, 62:586-590. 
28. Lazeron $\mathrm{RH}$, Langdon DW, Filippi $M$, van Waesberghe $J H$, Stevenson VL, Boringa JB, Origgi D, Thompson AJ, Falautano M, Polman CH, Barkhof F: Neuropsychological impairment in multiple sclerosis patients: the role of (juxta)cortical lesion on FLAIR. Mult Scler 2000, 6:280-285.

29. Moriarty DM, Blackshaw AJ, Talbot PR, Griffiths HL, Snowden JS, Hillier VF, Capener S, Laitt RD, Jackson A: Memory dysfunction in multiple sclerosis corresponds to juxtacortical lesion load on fast fluid-attenuated inversion-recovery MR images. AJNR Am J Neuroradiol 1999, 20:1956-1962.

30. Rovaris M, Filippi M, Minicucci L, lannucci G, Santuccio G, Possa F, Comi G: Cortical/subcortical disease burden and cognitive impairment in patients with multiple sclerosis. AJNR Am J Neuroradiol 2000, 21:402-408.

31. Sokic DV, Stojsavljevic N, Drulovic J, Dujmovic I, Mesaros S, Ercegovac M Peric V, Dragutinovic G, Levic Z: Seizures in multiple sclerosis. Epilepsia 2001, 42:72-79.

32. Spatt J, Chaix R, Mamoli B: Epileptic and non-epileptic seizures in multiple sclerosis. J Neurol 2001, 248:2-9.

33. Miller DH, Barkhof F, Frank JA, Parker GJ, Thompson AJ: Measurement of atrophy in multiple sclerosis: pathological basis, methodological aspects and clinical relevance. Brain 2002, 125:1676-1695.

34. Cercignani M, Bozzali M, lannucci G, Comi G, Filippi M: Magnetisation transfer ratio and mean diffusivity of normal appearing white and grey matter from patients with multiple sclerosis. J Neurol Neurosurg Psychiatry 2001, 70:311-317.

35. Davies GR, Ramio-Torrenta L, Hadjiprocopis A, Chard DT, Griffin CM, Rashid W, Barker GJ, Kapoor R, Thompson AJ, Miller DH: Evidence for grey matter MTR abnormality in minimally disabled patients with early relapsing-remitting multiple sclerosis. J Neurol Neurosurg Psychiatry 2004, 75:998-1002.

36. Fisniku LK, Altmann DR, Cercignani M, Tozer DJ, Chard DT, Jackson JS, Miszkiel KA, Schmierer K, Thompson AJ, Miller DH: Magnetization transfer ratio abnormalities reflect clinically relevant grey matter damage in multiple sclerosis. Mult Scler 2009, 15:668-677.

37. Ramio-Torrenta L, Sastre-Garriga J, Ingle GT, Davies GR, Ameen V, Miller DH, Thompson AJ: Abnormalities in normal appearing tissues in early primary progressive multiple sclerosis and their relation to disability: a tissue specific magnetisation transfer study. J Neurol Neurosurg Psychiatry 2006, 77:40-45.

38. Vrenken H, Geurts JJ, Knol DL, van Dijk LN, Dattola V, Jasperse B, van Schijndel RA, Polman CH, Castelijns JA, Barkhof F, Pouwels PJ: Whole-brain T1 mapping in multiple sclerosis: global changes of normal-appearing gray and white matter. Radiology 2006, 240:811-820.

39. Manfredonia F, Ciccarelli O, Khaleeli Z, Tozer DJ, Sastre-Garriga J, Miller DH, Thompson AJ: Normal-appearing brain $\mathrm{t} 1$ relaxation time predicts disability in early primary progressive multiple sclerosis. Arch Neurol 2007, 64:411-415.

40. Rovaris M, Gallo A, Valsasina P, Benedetti B, Caputo D, Ghezzi A, Montanari E, Sormani MP, Bertolotto A, Mancardi G, Bergamaschi R, Martinelli V, Comi G, Filippi M: Short-term accrual of gray matter pathology in patients with progressive multiple sclerosis: an in vivo study using diffusion tensor MRI. Neuroimage 2005, 24:1139-1146.

41. Vrenken H, Pouwels PJ, Geurts JJ, Knol DL, Polman CH, Barkhof F, Castelijns JA: Altered diffusion tensor in multiple sclerosis normalappearing brain tissue: cortical diffusion changes seem related to clinical deterioration. J Magn Reson Imaging 2006, 23:628-636.

42. Geurts JJ, Reuling IE, Vrenken H, Uitdehaag BM, Polman CH, Castelijns JA, Barkhof F, Pouwels PJ: MR spectroscopic evidence for thalamic and hippocampal, but not cortical, damage in multiple sclerosis. Magn Reson Med 2006, 55:478-483.

43. Kapeller P, McLean MA, Griffin CM, Chard D, Parker GJ, Barker GJ, Thompson AJ, Miller DH: Preliminary evidence for neuronal damage in cortical grey matter and normal appearing white matter in short duration relapsing-remitting multiple sclerosis: a quantitative MR spectroscopic imaging study. J Neurol 2001, 248:131-138.

44. Chard DT, Griffin CM, McLean MA, Kapeller P, Kapoor R, Thompson AJ, Miller DH: Brain metabolite changes in cortical grey and normalappearing white matter in clinically early relapsing-remitting multiple sclerosis. Brain 2002, 125:2342-2352

45. Jasperse B, Valsasina P, Neacsu V, Knol DL, De Stefano N, Enzinger C, Smith SM, Ropele S, Korteweg T, Giorgio A, Anderson V, Polman CH, Filippi M, Miller DH, Rovaris M, Barkhof F, Vrenken H: Intercenter agreement of brain atrophy measurement in multiple sclerosis patients using manually-edited SIENA and SIENAX. J Magn Reson Imaging 2007 26:881-885.

46. Smith SM, Zhang Y, Jenkinson M, Chen J, Matthews PM, Federico A, De Stefano N: Accurate, robust, and automated longitudinal and crosssectional brain change analysis. Neuroimage 2002, 17:479-489.

47. Ge Y, Grossman RI, Udupa JK, Babb JS, Nyul LG, Kolson DL: Brain atrophy in relapsing-remitting multiple sclerosis: fractional volumetric analysis of gray matter and white matter. Radiology 2001, 220:606-610.

48. Sailer M, Fischl B, Salat D, Tempelmann C, Schonfeld MA, Busa E, Bodammer N, Heinze HJ, Dale A: Focal thinning of the cerebral cortex in multiple sclerosis. Brain 2003, 126:1734-1744.

49. Calabrese M, Atzori M, Bernardi V, Morra A, Romualdi C, Rinaldi L, McAuliffe MJ, Barachino L, Perini P, Fischl B, Battistin L, Gallo P: Cortical atrophy is relevant in multiple sclerosis at clinical onset. J Neurol 2007, 254:1212-1220.

50. Calabrese M, Rinaldi F, Mattisi I, Grossi P, Favaretto A, Atzori M, Bernardi V, Barachino L, Romualdi C, Rinaldi L, Perini P, Gallo P: Widespread cortical thinning characterizes patients with MS with mild cognitive impairment. Neurology 2010, 74:321-328.

51. Chen JT, Narayanan S, Collins DL, Smith SM, Matthews PM, Arnold DL: Relating neocortical pathology to disability progression in multiple sclerosis using MRI. Neuroimage 2004, 23:1168-1175.

52. Pagani E, Rocca MA, Gallo A, Rovaris M, Martinelli V, Comi G, Filippi M: Regional brain atrophy evolves differently in patients with multiple sclerosis according to clinical phenotype. AJNR Am J Neuroradiol 2005, 26:341-346.

53. Sastre-Garriga J, Ingle GT, Chard DT, Cercignani M, Ramio-Torrenta L, Miller DH, Thompson AJ: Grey and white matter volume changes in early primary progressive multiple sclerosis: a longitudinal study. Brain 2005, 128:1454-1460

54. Roosendaal SD, Bendfeldt $\mathrm{K}$, Vrenken $\mathrm{H}$, Polman $\mathrm{CH}$, Borgwardt S, Radue EW, Kappos L, Pelletier D, Hauser SL, Matthews PM, Barkhof F, Geurts JJ: Grey matter volume in a large cohort of MS patients: relation to MRI parameters and disability. Mult Scler 2011.

55. De Stefano N, Matthews PM, Filippi M, Agosta F, De Luca M, Bartolozzi ML, Guidi L, Ghezzi A, Montanari E, Cifelli A, Federico A, Smith SM: Evidence of early cortical atrophy in MS: relevance to white matter changes and disability. Neurology 2003, 60:1157-1162.

56. Tedeschi G, Lavorgna L, Russo P, Prinster A, Dinacci D, Savettieri G, Quattrone A, Livrea P, Messina C, Reggio A, Bresciamorra V, Orefice G, Paciello M, Brunetti A, Coniglio G, Bonavita S, Di Costanzo A, Bellacosa A, Valentino P, Quarantelli M, Patti F, Salemi G, Cammarata E, Simone IL, Salvatore M, Bonavita V, Alfano B: Brain atrophy and lesion load in a large population of patients with multiple sclerosis. Neurology 2005, 65:280-285.

57. Dalton CM, Chard DT, Davies GR, Miszkiel KA, Altmann DR, Fernando K, Plant GT, Thompson AJ, Miller DH: Early development of multiple sclerosis is associated with progressive grey matter atrophy in patients presenting with clinically isolated syndromes. Brain 2004, 127:1101-1107.

58. Chard DT, Griffin CM, Rashid W, Davies GR, Altmann DR, Kapoor R, Barker GJ, Thompson AJ, Miller DH: Progressive grey matter atrophy in clinically early relapsing-remitting multiple sclerosis. Mult Scler 2004, 10:387-391.

59. Chard DT, Griffin CM, Parker GJ, Kapoor R, Thompson AJ, Miller DH: Brain atrophy in clinically early relapsing-remitting multiple sclerosis. Brain 2002, 125:327-337.

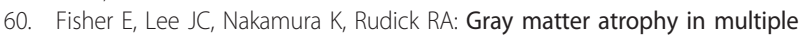
sclerosis: a longitudinal study. Ann Neurol 2008, 64:255-265.

61. Fisniku LK, Chard DT, Jackson JS, Anderson VM, Altmann DR, Miszkiel KA Thompson AJ, Miller DH: Gray matter atrophy is related to long-term disability in multiple sclerosis. Ann Neurol 2008, 64:247-254.

62. Amato MP, Portaccio E, Goretti B, Zipoli V, Battaglini M, Bartolozzi ML, Stromillo ML, Guidi L, Siracusa G, Sorbi S, Federico A, De Stefano N: Association of neocortical volume changes with cognitive deterioration in relapsing-remitting multiple sclerosis. Arch Neurol 2007, 64:1157-1161.

63. Benedict RH, Weinstock-Guttman B, Fishman I, Sharma J, Tjoa CW, Bakshi R: Prediction of neuropsychological impairment in multiple sclerosis: comparison of conventional magnetic resonance imaging measures of atrophy and lesion burden. Arch Neurol 2004, 61:226-230.

64. Benedict RH, Bruce JM, Dwyer MG, Abdelrahman N, Hussein S, WeinstockGuttman B, Garg N, Munschauer F, Zivadinov R: Neocortical atrophy, third 
ventricular width, and cognitive dysfunction in multiple sclerosis. Arch Neurol 2006, 63:1301-1306.

65. Tekok-Kilic A, Benedict RH, Weinstock-Guttman B, Dwyer MG, Carone D, Srinivasaraghavan B, Yella V, Abdelrahman N, Munschauer F, Bakshi R, Zivadinov R: Independent contributions of cortical gray matter atrophy and ventricle enlargement for predicting neuropsychological impairment in multiple sclerosis. Neuroimage 2007, 36:1294-1300

66. Rudick RA, Lee JC, Nakamura K, Fisher E: Gray matter atrophy correlates with MS disability progression measured with MSFC but not EDSS. J Neurol Sci 2009, 282:106-111.

67. Redpath TW, Smith FW: Technical note: use of a double inversion recovery pulse sequence to image selectively grey or white brain matter. Br J Radiol 1994, 67:1258-1263.

68. Turetschek K, Wunderbaldinger P, Bankier AA, Zontsich T, Graf O, Mallek R, Hittmair K: Double inversion recovery imaging of the brain: initial experience and comparison with fluid attenuated inversion recovery imaging. Magn Reson Imaging 1998, 16:127-135.

69. Geurts JJ, Pouwels PJ, Uitdehaag BM, Polman CH, Barkhof F, Castelijns JA: Intracortical lesions in multiple sclerosis: improved detection with 3D double inversion-recovery MR imaging. Radiology 2005, 236:254-260

70. Simon B, Schmidt S, Lukas C, Gieseke J, Traber F, Knol DL, Willinek WA, Geurts JJ, Schild HH, Wattjes MP: Improved in vivo detection of cortical lesions in multiple sclerosis using double inversion recovery MR imaging at 3 Tesla. Eur Radiol 2010, 20:1675-1683.

71. Bagnato F, Butman JA, Gupta S, Calabrese M, Pezawas L, Ohayon JM, TovarMoll F, Riva M, Cao MM, Talagala SL, McFarland HF: In vivo detection of cortical plaques by MR imaging in patients with multiple sclerosis. AJNR Am J Neuroradiol 2006, 27:2161-2167.

72. Calabrese M, Filippi M, Rovaris M, Bernardi V, Atzori M, Mattisi I, Favaretto A, Grossi P, Barachino L, Rinaldi L, Romualdi C, Perini P, Gallo P: Evidence for relative cortical sparing in benign multiple sclerosis: a longitudinal magnetic resonance imaging study. Mult Scler 2009, 15:36-41.

73. Calabrese M, Rocca MA, Atzori M, Mattisi I, Favaretto A, Perini P, Gallo P, Filippi M: A 3-year magnetic resonance imaging study of cortical lesions in relapse-onset multiple sclerosis. Ann Neurol 2010, 67:376-383.

74. Calabrese M, Battaglini M, Giorgio A, Atzori M, Bernardi V, Mattisi I, Gallo P, De Stefano N: Imaging distribution and frequency of cortical lesions in patients with multiple sclerosis. Neurology 2010, 75:1234-1240.

75. Calabrese M, Rocca MA, Atzori M, Mattisi I, Bernardi V, Favaretto A, Barachino L, Romualdi C, Rinaldi L, Perini P, Gallo P, Filippi M: Cortical lesions in primary progressive multiple sclerosis: a 2-year longitudinal MR study. Neurology 2009, 72:1330-1336.

76. Calabrese M, De Stefano N, Atzori M, Bernardi V, Mattisi I, Barachino L, Morra A, Rinaldi L, Romualdi C, Perini P, Battistin L, Gallo P: Detection of cortical inflammatory lesions by double inversion recovery magnetic resonance imaging in patients with multiple sclerosis. Arch Neurol 2007, 64:1416-1422.

77. Roosendaal SD, Moraal B, Pouwels PJ, Vrenken H, Castelijns JA, Barkhof F, Geurts JJ: Accumulation of cortical lesions in MS: relation with cognitive impairment. Mult Scler 2009, 15:708-714.

78. Nelson F, Datta S, Garcia N, Rozario NL, Perez F, Cutter G, Narayana PA, Wolinsky JS: Intracortical lesions by $3 \mathrm{~T}$ magnetic resonance imaging and correlation with cognitive impairment in multiple sclerosis. Mult Scler 2011.

79. Calabrese M, Agosta F, Rinaldi F, Mattisi I, Grossi P, Favaretto A, Atzori M, Bernardi V, Barachino L, Rinaldi L, Perini P, Gallo P, Filippi M: Cortical lesions and atrophy associated with cognitive impairment in relapsing-remitting multiple sclerosis. Arch Neurol 2009, 66:1144-1150.

80. Calabrese M, Filippi M, Rovaris M, Mattisi I, Bernardi V, Atzori M, Favaretto A, Barachino L, Rinaldi L, Romualdi C, Perini P, Gallo P: Morphology and evolution of cortical lesions in multiple sclerosis. A longitudinal MRI study. Neuroimage 2008, 42:1324-1328.

81. Geurts JJ, Roosendaal SD, Calabrese M, Ciccarelli O, Agosta F, Chard DT, Gass A, Huerga E, Moraal B, Pareto D, Rocca MA, Wattjes MP, Yousry TA, Uitdehaag BM, Barkhof F: Consensus recommendations for MS cortical lesion scoring using double inversion recovery MRI. Neurology 2011, 76:418-424.

82. Seewann A, Kooi EJ, Roosendaal SD, Pouwels PJ, Wattjes MP, van der Valk $P$, Barkhof F, Polman CH, Geurts JJ: Post mortem verification of MS cortical lesion detection with 3D-DIR. Neurology 2011.
83. Seewann A, Vrenken H, Kooi EJ, van d V, Knol DL, Polman CH, Pouwels PJ, Barkhof F, Geurts JJ: Imaging the tip of the iceberg: visualization of cortical lesions in multiple sclerosis. Mult Scler 2011.

84. Nelson F, Poonawalla A, Hou P, Wolinsky JS, Narayana PA: 3D MPRAGE improves classification of cortical lesions in multiple sclerosis. Mult Scler 2008, 14:1214-1219.

85. Nelson F, Poonawalla AH, Hou P, Huang F, Wolinsky JS, Narayana PA: Improved identification of intracortical lesions in multiple sclerosis with phase-sensitive inversion recovery in combination with fast double inversion recovery MR imaging. AJNR Am J Neuroradiol 2007, 28:1645-1649.

86. Pitt D, Boster A, Pei W, Wohleb E, Jasne A, Zachariah CR, Rammohan K, Knopp MV, Schmalbrock P: Imaging cortical lesions in multiple sclerosis with ultra-high-field magnetic resonance imaging. Arch Neurol 2010, 67:812-818.

87. Kangarlu A, Bourekas EC, Ray-Chaudhury A, Rammohan KW: Cerebral cortical lesions in multiple sclerosis detected by MR imaging at 8 Tesla. AJNR Am J Neuroradiol 2007, 28:262-266.

88. Schmierer K, Parkes HG, So PW, An SF, Brandner S, Ordidge RJ, Yousry TA, Miller DH: High field (9.4 Tesla) magnetic resonance imaging of cortical grey matter lesions in multiple sclerosis. Brain 2010, 133:858-867.

89. Kollia K, Maderwald S, Putzki N, Schlamann M, Theysohn JM, Kraff O, Ladd ME, Forsting M, Wanke I: First clinical study on ultra-high-field MR imaging in patients with multiple sclerosis: comparison of $1.5 \mathrm{~T}$ and $7 \mathrm{~T}$. AJNR Am J Neuroradiol 2009, 30:699-702.

90. Metcalf M, Xu D, Okuda DT, Carvajal L, Srinivasan R, Kelley DA, Mukherjee P, Nelson SJ, Vigneron DB, Pelletier D: High-resolution phased-array MRI of the human brain at 7 tesla: initial experience in multiple sclerosis patients. J Neuroimaging 2010, 20:141-147.

91. Mainero C, Benner T, Radding A, van der KA, Jensen R, Rosen BR, Kinkel RP: In vivo imaging of cortical pathology in multiple sclerosis using ultrahigh field MRI. Neurology 2009, 73:941-948.

92. Tallantyre EC, Morgan PS, Dixon JE, Al Radaideh A, Brookes MJ, Morris PG, Evangelou N: 3 Tesla and 7 Tesla MRI of multiple sclerosis cortical lesions. J Magn Reson Imaging 2010, 32:971-977.

93. Bermel RA, Innus MD, Tjoa CW, Bakshi R: Selective caudate atrophy in multiple sclerosis: a 3D MRI parcellation study. Neuroreport 2003, 14:335-339.

94. Prinster A, Quarantelli M, Orefice G, Lanzillo R, Brunetti A, Mollica C, Salvatore E, Morra VB, Coppola G, Vacca G, Alfano B, Salvatore M: Grey matter loss in relapsing-remitting multiple sclerosis: a voxel-based morphometry study. Neuroimage 2006, 29:859-867.

95. Geurts JJ, Bo L, Roosendaal SD, Hazes T, Daniels R, Barkhof F, Witter MP, Huitinga I, van der Valk P: Extensive hippocampal demyelination in multiple sclerosis. J Neuropathol Exp Neurol 2007, 66:819-827.

96. Huitinga I, De Groot CJ, van d V, Kamphorst W, Tilders FJ, Swaab DF: Hypothalamic lesions in multiple sclerosis. J Neuropathol Exp Neurol 2001, 60:1208-1218.

97. Huitinga I, Erkut ZA, van Beurden D, Swaab DF: Impaired hypothalamuspituitary-adrenal axis activity and more severe multiple sclerosis with hypothalamic lesions. Ann Neurol 2004, 55:37-45.

98. Ceccarelli A, Rocca MA, Pagani E, Colombo B, Martinelli V, Comi G, Filippi M A voxel-based morphometry study of grey matter loss in MS patients with different clinical phenotypes. Neuroimage 2008, 42:315-322.

99. Houtchens MK, Benedict RH, Killiany R, Sharma J, Jaisani Z, Singh B, Weinstock-Guttman B, Guttmann CR, Bakshi R: Thalamic atrophy and cognition in multiple sclerosis. Neurology 2007, 69:1213-1223.

100. Cifelli A, Arridge M, Jezzard P, Esiri MM, Palace J, Matthews PM: Thalamic neurodegeneration in multiple sclerosis. Ann Neurol 2002, 52:650-653.

101. Davies GR, Altmann DR, Rashid W, Chard DT, Griffin CM, Barker GJ, Kapoor R, Thompson AJ, Miller DH: Emergence of thalamic magnetization transfer ratio abnormality in early relapsing-remitting multiple sclerosis. Mult Scler 2005, 11:276-281.

102. Wylezinska M, Cifelli A, Jezzard P, Palace J, Alecci M, Matthews PM: Thalamic neurodegeneration in relapsing-remitting multiple sclerosis. Neurology 2003, 60:1949-1954

103. Ramasamy DP, Benedict RH, Cox JL, Fritz D, Abdelrahman N, Hussein S, Minagar A, Dwyer MG, Zivadinov R: Extent of cerebellum, subcortical and cortical atrophy in patients with MS: a case-control study. J Neurol Sci 2009, 282:47-54 
104. Rocca MA, Mesaros S, Pagani E, Sormani MP, Comi G, Filippi M: Thalamic damage and long-term progression of disability in multiple sclerosis. Radiology 2010, 257:463-469.

105. Fabiano AJ, Sharma J, Weinstock-Guttman B, Munschauer FE, Benedict RH, Zivadinov $R$, Bakshi $R$ : Thalamic involvement in multiple sclerosis: a diffusion-weighted magnetic resonance imaging study. J Neuroimaging 2003, 13:307-314.

106. Carone DA, Benedict RH, Dwyer MG, Cookfair DL, Srinivasaraghavan B, Tjoa CW, Zivadinov R: Semi-automatic brain region extraction (SABRE) reveals superior cortical and deep gray matter atrophy in MS. Neuroimage 2006, 29:505-514.

107. Calabrese M, Rinaldi F, Grossi P, Mattisi I, Bernardi V, Favaretto A, Perini P, Gallo P: Basal ganglia and frontal/parietal cortical atrophy is associated with fatigue in relapsing-remitting multiple sclerosis. Mult Scler 2010, 16:1220-1228.

108. Audoin B, Zaaraoui W, Reuter F, Rico A, Malikova I, Confort-Gouny S, Cozzone PJ, Pelletier J, Ranjeva JP: Atrophy mainly affects the limbic system and the deep grey matter at the first stage of multiple sclerosis. J Neurol Neurosurg Psychiatry 2010, 81:690-695.

109. Mesaros S, Rocca MA, Absinta M, Ghezzi A, Milani N, Moiola L, Veggiotti $P$, Comi G, Filippi M: Evidence of thalamic gray matter loss in pediatric multiple sclerosis. Neurology 2008, 70:1107-1112.

110. Tao G, Datta S, He R, Nelson F, Wolinsky JS, Narayana PA: Deep gray matter atrophy in multiple sclerosis: a tensor based morphometry. $J$ Neurol Sci 2009, 282:39-46.

111. Audoin B, Davies GR, Finisku L, Chard DT, Thompson AJ, Miller DH: Localization of grey matter atrophy in early RRMS: A longitudinal study. J Neurol 2006, 253:1495-1501.

112. Henry RG, Shieh M, Okuda DT, Evangelista A, Gorno-Tempini ML, Pelletier D: Regional grey matter atrophy in clinically isolated syndromes at presentation. J Neurol Neurosurg Psychiatry 2008, 79:1236-1244.

113. Sepulcre J, Sastre-Garriga J, Cercignani M, Ingle GT, Miller DH, Thompson AJ: Regional gray matter atrophy in early primary progressive multiple sclerosis: a voxel-based morphometry study. Arch Neurol 2006, 63:1175-1180.

114. Till C, Ghassemi R, Aubert-Broche B, Kerbrat A, Collins DL, Narayanan S, Arnold DL, Desrocher M, Sled JG, Banwell BL: MRI correlates of cognitive impairment in childhood-onset multiple sclerosis. Neuropsychology 2011 25:319-332.

115. Papadopoulos D, Dukes S, Patel R, Nicholas R, Vora A, Reynolds R: Substantial archaeocortical atrophy and neuronal loss in multiple sclerosis. Brain Pathol 2009, 19:238-253.

116. Roosendaal SD, Moraal B, Vrenken H, Castelijns JA, Pouwels PJ, Barkhof F, Geurts JJ: In vivo MR imaging of hippocampal lesions in multiple sclerosis. J Magn Reson Imaging 2008, 27:726-731.

117. Anderson VM, Fisniku LK, Khaleeli Z, Summers MM, Penny SA, Altmann DR, Thompson AJ, Ron MA, Miller DH: Hippocampal atrophy in relapsingremitting and primary progressive MS: a comparative study. Mult Scler 2010, 16:1083-1090.

118. Sicotte NL, Kern KC, Giesser BS, Arshanapalli A, Schultz A, Montag M, Wang $\mathrm{H}$, Bookheimer SY: Regional hippocampal atrophy in multiple sclerosis. Brain 2008, 131:1134-1141.

119. Audoin B, Au Duong MV, Ranjeva JP, Ibarrola D, Malikova I, ConfortGouny S, Soulier E, Viout P, Ali-Cherif A, Pelletier J, Cozzone PJ: Magnetic resonance study of the influence of tissue damage and cortical reorganization on PASAT performance at the earliest stage of multiple sclerosis. Hum Brain Mapp 2005, 24:216-228.

120. Audoin B, Reuter F, Duong MV, Malikova I, Confort-Gouny S, Cherif AA, Cozzone PJ, Pelletier J, Ranjeva JP: Efficiency of cognitive control recruitment in the very early stage of multiple sclerosis: a one-year fMRI follow-up study. Mult Scler 2008, 14:786-792.

121. Mainero C, Caramia F, Pozzilli C, Pisani A, Pestalozza I, Borriello G, Bozzao L, Pantano P: fMRI evidence of brain reorganization during attention and memory tasks in multiple sclerosis. Neuroimage 2004, 21:858-867.

122. Rocca MA, Valsasina P, Ceccarelli A, Absinta M, Ghezzi A, Riccitelli G, Pagani E, Falini A, Comi G, Scotti G, Filippi M: Structural and functional MRI correlates of Stroop control in benign MS. Hum Brain Mapp 2009, 30:276-290.

123. Penner IK, Rausch M, Kappos L, Opwis K, Radu EW: Analysis of impairment related functional architecture in MS patients during performance of different attention tasks. J Neurol 2003, 250:461-472.
124. Rocca MA, Valsasina $P$, Absinta M, Riccitelli $G$, Rodegher ME, Misci $P$, Rossi P, Falini A, Comi G, Filippi M: Default-mode network dysfunction and cognitive impairment in progressive MS. Neurology 2010, 74:1252-1259.

125. Bobholz JA, Rao SM, Lobeck L, Elsinger C, Gleason A, Kanz J, Durgerian S, Maas E: fMRI study of episodic memory in relapsing-remitting MS: correlation with T2 lesion volume. Neurology 2006, 67:1640-1645.

126. Roosendaal SD, Hulst HE, Vrenken H, Feenstra HE, Castelijns JA, Pouwels PJ, Barkhof F, Geurts JJ: Structural and functional hippocampal changes in multiple sclerosis patients with intact memory function. Radiology 2010, 255:595-604.

127. Hulst HE, Schoonheim MM, Roosendaal SD, Popescu V, Schweren L, van der Werf YD, Visser LH, Polman CH, Barkhof F, Geurts JJ: Functional adaptive changes within the hippocampal memory system of patients with multiple sclerosis. Hum Brain Mapp 2011

128. Tsunoda I, Fujinami RS: Inside-Out versus Outside-In models for virus induced demyelination: axonal damage triggering demyelination. Springer Semin Immunopathol 2002, 24:105-125.

129. Geurts JJ, Stys PK, Minagar A, Amor S, Zivadinov R: Gray matter pathology in (chronic) MS: modern views on an early observation. J Neurol Sci 2009, 282:12-20

130. Bo L, Geurts JJ, van d V, Polman C, Barkhof F: Lack of correlation between cortical demyelination and white matter pathologic changes in multiple sclerosis. Arch Neurol 2007, 64:76-80.

131. Geurts JJ, Barkhof F: Grey matter pathology in multiple sclerosis. Lancet Neurol 2008, 7:841-851

\section{Pre-publication history}

The pre-publication history for this paper can be accessed here: http://www.biomedcentral.com/1471-2377/11/153/prepub

doi:10.1186/1471-2377-11-153

Cite this article as: Hulst and Geurts: Gray matter imaging in multiple sclerosis: what have we learned? BMC Neurology 2011 11:153.

\section{Submit your next manuscript to BioMed Central and take full advantage of:}

- Convenient online submission

- Thorough peer review

- No space constraints or color figure charges

- Immediate publication on acceptance

- Inclusion in PubMed, CAS, Scopus and Google Scholar

- Research which is freely available for redistribution 